\title{
On the Gymnastics of Memory: Stiegler, Positive Pharmacology, and Illiteracy
}

\author{
Joff P. N. Bradley ${ }^{1}$ (D)
}

Received: 19 November 2020 / Accepted: 13 February 2021 / Published online: 24 February 2021

(c) New Zealand Association for Research in Education 2021

\begin{abstract}
Here I shall write about the late Bernard Stiegler (1952-2020) and contextualize this important philosopher's work with respect to the concrete, everyday pedagogical issue of language learning. To demonstrate Stiegler's applicability to education studies, I shall address the issue of character amnesia (提筆忘字, tibiwangzi in Chinese, literally "pick up pen, forget the character"), a relatively recent phenomenon experienced in China and Japan, which is concerned with the loss of the ability to write and remember Chinese ideograms. I shall use tibiwangzi as a striking and heuristic example to explain the growing crisis in literacy, that is the crisis in the ability to read and write. Tibiwangzi is a Stieglerian issue of vital importance. In this light, my focus will be on language learning and literacy and I shall couch my analysis regarding this in terms of both Stiegler's thoughts on tertiary, exteriorized memory and the neuroscientist Maryanne Wolf's concern with the neurological and cognitive effects of reading. I intend to focus on the apparent rupture or disruption between traditional writing systems (alphabetic writing) and digital technologies and argue that a pharmacological understanding of technology and therefore a consideration of Stiegler's work in the light of neuroscience, memory and digital technologies, is necessary as it can spark timely and critical research into the perceived crisis of literacy. I am making the case for what I am naming a gymnastics of memory.
\end{abstract}

Keywords Stiegler $\cdot$ Guattari $\cdot$ Neuroscience $\cdot$ Memory $\cdot$ Character amnesia Literacy

\section{Introduction}

I start with a quote to which I often turn. It is by the militant psychiatrist and philosopher Félix Guattari (1930-1992) - a writer who influenced Stiegler a great deal. In the short essay On Machines, originally published in French in Chimeres

Joff P. N. Bradley

joff@main.teikyo-u.ac.jp

1 Teikyo University, Hachioji Campus, Faculty of Foreign Languages, Tokyo 192-0395, Japan 
in 1993, Guattari (Benjamin, 1995, p. 11) writes presciently albeit without full knowledge of the Internet revolution to come in the decades ahead:

Today, children who are learning language from a word-processor are no longer within the same types of universes of reference as before, neither from a cognitive point of view (of how there may be another organisation of memory, or rather memories...), nor in the order of affective dimensions and social or ethical relationships.

The quotation is extremely important because Guattari discusses his concept of "new universes of reference" [nouveaux Univers de référence], a concept he understands cognitively, mnemonically, affectively, socially and ethically, and which forms part of his materialist, diagrammatic and ecosophical thinking (Guattari, 2014). Guattari was writing on the cusp of the technological revolution which the World Wide Web would bring and his observations are in many ways consistent with Stiegler's philosophy of technology and have important consequences for the philosophy of education. Guattari's observation that different technologies prise open different "universes of reference" is consistent with Stiegler's concern with the pharmacology of digital technologies, that is to say, how technologies open up or close down thinking as such. The pharmakon, a concept from Plato's philosophy, is used by Stiegler and his teacher Jacques Derrida to explore how a thing can be at once a poison and cure or therapy.

Yet in disagreement with French neuroscientist Jean-Pierre Changeux, who argues that the cultural cannot be thought of without the biological and that the cerebral is always an interplay with the environment, Stiegler asks if the reverse were not true: "Wouldn't it be necessary, more precisely, to speak firstly of technique, and of its organs, and of the relationship between technical organs and biological organs, before questioning culture itself?" (Wolf et al., 2015, p.13 my trans). What follows from this is the necessity to examine the conditions under which culture appears in the first place, namely the transformation of organogenesis and the appearance of the tools or exosomatization, that is the recording of memories outside the brain.

Following Plato, we can observe that pharmacology is at once a poison and a cure (Stiegler, 2014a). In other words, digital technologies can become toxic or open new vistas and new ways of thinking (Bradley, 2018). Technologies can lead to gains in new knowledge or lead detrimentally to proletarianization, which is to say following Marx in the Grundrisse, to the loss of skills and know-how, what Stiegler calls the saviors. What we need to understand here is how technology can either assist literacy or accelerate illiteracy levels.

Given the pre-Internet timing and prescience of the essay by Guattari above, it is noteworthy to see how Stiegler and Guattari share similar concerns regarding the impacts of new technologies on learning and knowledge production as such. On the question of the ramifications of reticular, that is, networked, reading and writing (l'écriture réticulaire or écriture numérique), which we should understand as the analysis - detrimental or otherwise — of informatized media, online reading practices, the writing of code as such, Stiegler writes (Stiegler, 2014a, b): 
With the advent of reticular reading and writing (Herrenschmidt, 2007) via networks made accessible to everyone through the implementation, beginning in 1993, of the technologies of the World Wide Web, digital technologies have led hyperindustrial societies toward a new stage of proletarianization-through which the hyperindustrial age becomes the era of systemic stupidity.

In his analysis of new processes of grammatization, that is how memory is recorded and retained artificially, Stiegler claims digital tertiary retention (the exteriorization of memory in vast computer databases for example) is a new form of writing. The digital is a form of reticular writing, "which is also and firstly however, a networked reading" (Stiegler and Ross, 2017, p. 256). Stiegler follows Clarisse Herrenschmidt (2007), whose tripartite analysis of graphical history notes three chief inventions (1) the first writing of language around 3200 B.C; (2) the writing of numbers, around 620 B.C., and (3) the writing of code in computerized writing beginning in the 1930s, and later with the advent of reticular writing in 1969-and warns that the current iteration of digital technology and therefore its reticular writing practices infringe upon what we classically consider to be thinking as such. In reticular writing, thinking as such is in danger of being eroded by the automation of thought and the relegation or outsourcing of memory to exosomatic organs. In some ways akin to the structure of Guattari's three ecologies thesis (Guattari, 2014), the psyche, environment, and technology are reticulated or networked in manifestly toxic and deleterious ways. In comparing Guattari and Stiegler my point here is that language, number and code do not necessarily reside in the equivalent semiological universe. As different forms of graphical representation of thought clearly impact on the thinking processes of the human, the question at stake here is whether there are non-reticular practices involved in digital writing such as writing in new universes of references such as the word processor. In terms of écriture numérique or reticulated writing the question is what are the ramifications of digital technologies (via technical and social devices such as the smartphone) on writing and reading practices? Put at its simplest, will forms of reticular writing short-circuit or bypass the capacity to think by and for oneself?

In his reflections on the organology of the brain, Stiegler is concerned with the disruptive effects of the new era of innovation on the digital brain "where exosomatization is now totally controlled by economic powers, and subject to their shortterm profitability constraints" (Wolf et al., 2015, p. 19 my trans). The effects on the digital brain are taking place at a dazzling pace and for Stiegler this raises the question of the preservation and capacity of deep reading. He asks: "Will we be able to take care of the reading brain which becomes digital without losing our sanity?" (Wolf et al., 2015, p. 19 my trans).

\section{On the Gymnastics of Hyper-Spastic Movement}

What does it mean for contemporary society and its members to forget how to sit down, to write with only a pen and paper; to fail to gather one's own thoughts into some comprehensible sense? At first glance and for the most part, it seems to signal the end of society as such, for under such conditions one cannot pass on 
learning and culture and therefore reasoning to the next generation. In Stiegler's language, following Gilbert Simondon, this is the crisis of transindividuation circuits between the generations. The ramifications for society's language and culture are stark. I put my argument expressively and expansively so because I am writing to you thousands of miles away, surrounded and entangled by screens and cables and microphones and all other such clutter. The day before I was thumbing thoughts on my smartphone on a jam-packed train at six in the morning during my commute across Tokyo. In fact, at present, I am talking into the microphone and the smartphone, with its hardware and software, and the vast speech dictation databases held on computers across the planet, work in tandem to transcribe into text my whispers, groans and mumbles and other involuntary and inarticulate sounds which come from my mouth. Words and sentences magically and immediately appear on my screen. After a little bit of editing words become sentences, sentences become paragraphs and paragraphs turn into pages and then pages into essays and books. Everything is stored on my computer and smartphone in the so-called cloud or in data storage facilities across the planet whose location I am blissfully unaware. Of course, in some ways my writing does not exist until I hit the print button and then, voila!, at least somewhere in the material world my writing takes on a presence in paper form. This is I suspect how many scholars do research nowadays. Indeed, it is also how Stiegler sometimes did his research by transcribing the thoughts which came forth as he exercised on his bicycle around his local village. I suspect this is how many young people write essays for their teachers nowadays, at speed, on the go, on the mobile. We write down memos or talk into our mobile phones, which store our voices or badly typed textual ideas. Verily, our thoughts are elsewhere, not in our heads, but in our machines. Our thoughts are decapitated. When we get home or to the office, we extract these immaterial entities which are recorded on our portable machines and save them elsewhere. In Stiegler's language, following Husserl, we draw on digital tertiary retentions; that is, memories stored in vast databases. This is, in itself, amazing. In fact, if I were to pick up a pen right now to write down these very thoughts I would have great difficulty in keeping my concentration. I am sure something else would been produced. I am equally sure that if I were to write these thoughts on a word processor, a smartphone, or an old typewriter, my thoughts would take on a different trajectory. Guattari would say that I would inhabit a different universe of reference. I know this, and moreover, it would take an inordinate amount of time. I would need to be without distraction. I would need to sit still. I would need to be attentive to what is before me (Heidegger, 1968, 1992). Most definitely, I would need to approach the question of thinking and writing from the experience I once had (Bradley, 2014). Of course, I know I can somehow do this or at least I can learn to do this again. I can write an essay with a pen and paper in the old way as I once did as a student. I can read the way I once did. However, after this process I would have to type it up into an electronic version to be again sent into the ether to reach the computers of colleagues and professors based elsewhere. This would be very idiosyncratic, taxing, time consuming and hence ultimately counterproductive. 


\section{Character Amnesia and the Destruction of Language}

Let me here turn to the question of character amnesia which has become a daunting reality in many societies across the globe (Almog, 2018, 2019; Zhou et al., 2020). Researchers suggest the growing reliance on digital technologies is leading to the declining ability to handwrite Chinese characters. This is a phenomenon concerned with the loss of the ability to write and remember traditional letters like Chinese ideograms. We shall say in Stiegler's argot it is leading to the loss of savoir faire (knowledge of how to do). While this appears to have become a pressing reality in the decades since the World Wide Web first became widely available to people across the planet in the early 1990s, it is not without precedent. The concern with the move away from oral recollection to reading and writing and inscription can be found with ancient Greek philosophy and especially with Plato and Socrates. My concern here is to draw out the ramifications of character amnesia in light of Stiegler's philosophy. It seems to me this phenomenon can be critically assessed vis-àvis Stiegler's thoughts on tertiary memory and the neuroscientist Wolf's concern with the neurological and cognitive effects of reading (Wolf, 2019). Stiegler has collaborated with Wolf to understand how the brain is affected by reading and indeed wrote the preface for the French translation of Wolf's Proust and the Squid (Wolf et al., 2015). He writes on the crises in education and the elementary albeit declining skill in reading and writing:

We are very concerned nowadays about what becomes of educational establishments and the difficulties they encounter in training the younger generations for which they are responsible. We are right to be concerned about this. If education is so fundamental for us and our children, it is because each new generation, everything that has been learned by previous generations must be appropriated by newcomers, which is only possible on condition that they first prepare their cerebral organ by subjecting it to so-called elementary learning, that is to say allowing them to enter in the basic element of knowledge, which in this case, in the West, and for nearly three thousand years, is alphabetical writing-first handwritten, then printed. (Wolf et al., 2015, p.18 my trans)

Stiegler is primarily interested in how neuroscience can be used to make sense of the addiction and intoxication with digital technologies. Tibiwangzi or character amnesia is a striking phenomenon which allows us to ruminate on the rupture or disruption between traditional writing systems and digital technologies. At stake is the question of the toxicity of the "global mnemotechnical system" (see Stiegler, 2015a) - that is the World Wide Web in its current iteration-and its possible curative and therapeutic capacities.

As I work and live in Japan, a nation which has enjoyed high levels of literacy historically, I understand character amnesia in the context of computer-induced agraphia or the difficulty in writing and spelling due to prolonged typing on digital devices. Critics insist this is leading to the decline in kanji writing and reading abilities. The Japanese media once had a buzzword for this—wäpurobaka ( ープロ馬鹿, literally "word-processor idiot")—(Almog, 2019)—that is, if you use a word processor you turn into an idiot. I used the past tense in the last sentence 
because contemporary societies have a new phenomenon-the "smartphone idiot." Indeed, way back in the 1990s, Plant (2003) was exploring how children across the world use their thumbs effortlessly and unconsciously, with little need to look at the keys as they entered text. Thumbs were becoming more muscled and dextrous and more widely used than index fingers. Japanese children were consequently dubbed the "thumb tribe" or "thumb generation." Thumbs were used ambidextrously, in a completely different way, according to Plant. This form of unconscious reflex action is consistent with Stiegler's perspective on bêtise or stupidity, which is accelerating and worsening the reality of "character amnesia" (Bradley, 2015; Cole and Bradley, 2017). My point here is not to patronise young people but to take stock of the revolutionary transformations taking place which need to be accounted for and critiqued (Bradley, 2020). Character amnesia is an expression of the changing contours of grammatization, that is to say, the process of formalizing expression into letters, words, writing, and abstract code (Stiegler, 2011; Tinnell, 2015). For Stiegler, the stakes are grave, because our contemporary moment is witnessing a digitalized grammatization process which disrupts all educational activities and leads to a colossal transformation of and disruption of knowledge. In its wake, what is the cure or can there be a cure for character amnesia?

When Stiegler writes that our lives are "completely overdetermined by automatization" (Stiegler and Nony, 2015), for example, through the smartphone, what does he mean? Stiegler argues that the smartphone, as a toxic "industrial temporal object" (see During et al., 2017) intercedes between the mother and the child for example so that the child learns toxically more from a machine than from a parent. Affirming this new relationship as Michel Serres appears to do in Thumberlina is "scandalous" according to Stiegler (2014b). As a consequence, the parent must compete with a machine for the attention of the child. The child's attention is elsewhere, communing with addictive and toxic digital technologies led by the marketing industries. Stiegler goes on to say that the child seeing his parent entranced with this handheld device yearns for access to this addictive object, a transitional object in the language of Winnicott, and without it the child enters a state of withdrawal. Such is the nature of this toxic form of digital apparatus. What does this mean for the philosophy of education? What can we learn from Stiegler's philosophy and how can we use it to create instruments or tools pharmacologically, to transform and care for the attention of the learner? What is the cure for this state of addiction and intoxication? Stiegler (2015b) puts it bluntly in the title of one of his discussions: "We have to get out of our addictive and stupid relationship with digital instruments." Indeed, this argument is akin to the one given by Franco Berardi (2012, p. 101) who observes that in the late 1970s children came to learn more from a machine than its mother.

The techno-linguistic machine is giving language to human beings, and also taking the place of human beings in language for the current generation. The first generation that learned more words from a machine than from their mothers has a problem concerning the relationship between words and the body, between words and affection. The separation of language learning from the body of the mother and from the body in general is changing language itself, and is changing the relationship between language and the body. 
One finds a consistent demand in Stiegler's philosophy to find new ways of thinking about our relationship to technology and, in particular, to question algorithmic governmentality (Rouvroy and Stiegler, 2016) and écriture numérique. In its toxic state, addiction is an "absolutely colossal problem" (Stiegler, 2015b). For Stiegler, we must escape this form of addiction and find instead curative, therapeutic forms of positive addiction, positive pharmacologies. Love would be an example of a positive addiction. Study would be another. There are other beautiful addictions. A painter paints. A musician creates sound after sound. A philosopher creates concepts. Life in its beautiful mode is full of addiction is Stiegler's consistent refrain.

Here the role of the amateur is important. Stiegler traces the etymology of the amateur as one who loves, who has a taste for something, as one who cultivates. The amateur is a mediator, a writer, a curator, one who improvises and one who resists in the age of generalized proletarianization, becoming less consumer and more active participant and producer. Importantly, says Stiegler, l'amateur est une figure $d u$ désir, et le désir est addictif [the amateur is a figure of desire, and desire is addictive] (Rochard et al., 2020). For a society to be without desire, without sublimation, without the tethering of the drives to desire itself, is tantamount to its becoming uncontrollable (Stiegler, 2012b).

Stiegler's point is that we have to learn to escape our negative addictions and find positive ones. In this way, we have to escape our intoxicated, stupid and repetitive relationships with digital instruments. This is the pharmacology of digital technologies. In the documentary Technologies of Spirit (Heathfield et al., 2015), Stiegler insists we must invent with our devices not in a passive or consumerist mode but produce and invent new forms of knowledge or forms of negentropic knowledge. This he calls an "organology of sensibility" and claims that our sensibility as such is shaped and educated through instruments and technical objects, through different kinds of formation of attention, but in the 20th century, technologies of sensibility are catastrophically producing cognitive proletarianization or loss of knowledge as such. What is essential is to understand the pharmacological dimension of technology, to use the poison of technology therapeutically, to contribute and to share knowledge production as such. At its most affirmative, for Stiegler, this can manifest "a new political vision of the future."

Both Stiegler and Marianne Wolf are concerned with what is happening to the brains of children who use transitional and industrial temporal objects to dangerous and negative effect. At its worst, young children are not learning, reading, writing or remembering language but are merely occupied and addicted-and as such nothing is trans-formed, sublimnated and created. Wolf is at pains to show that when reading the working memory is a hive of activity or seat of mental work, where the criteria of selection vis-à-vis the semantic possibilities of the text, is the ground for active reinterpretation and even reorganization of a work.

If children are given over to digital technologies without care and attention to their deleterious effects, this is a disaster because there is no creative process of individuation and subjectivation between the object and the user. Stiegler decries such a state in which the brains of young children are becoming deserted of memory. He questions the addiction, compulsion and dependence on machines and our increasingly noetic convulsion to counting, reading, writing, to simply thinking 
for ourselves. Character amnesia is an obvious instance of this trend. Simply put, Stiegler questions the conspicuous lack of creative intelligence and in its wake he calls for the reconfiguration of knowledge: in short, we must completely reinvent education.

What is the remedy for the loss of the ability to read and write, not only in the Japanese and Chinese context but further afield? Stiegler's point is that we cannot, even if we wished to, escape the reality of the digital technological world. There is no dogmatic Luddite manifesto in his writing. Rather we must use digital technologies pharmacologically, therapeutically, curatively, "be stirring as the time; be fire with fire" as Shakespeare says. For his part, Stiegler says fire, man's originary technicity (Stiegler, 1998), is man's fate and lot and thus we must use our technicity wisely. Tékhnē ( $\tau \dot{\varepsilon} \chi \nu \eta)$ is first philosophy.

\section{Desperate Anecdote}

All my students have smartphones. As soon as my class finishes, they rush out of the classroom to check their messages. Day in day out, I admit that I struggle to command their attention. How can I improve their literacy if their minds are elsewhere? I fear it is quite possible that they can graduate from university without reading a book-in whatever language. This is a disastrous state of affairs. This is why my paper is called the gymnastics of memory. We need to re-imagine this gymnastics of memory as an ascetics of solitude and silence. On this point, Stiegler shares a similar concern and discusses the need to preserve the exceptional use of language:

The impoverishment of vocabulary and dysorthography [a specific disorder of spelling] regresses individual and collective intelligence through a submission to the law of averages. Conversely, life produces, through exceptions, mutations that are impossible to anticipate but which are the very conditions of evolution. Poets and writers have shaped languages through their exceptional use of language. Algorithms erase all exceptions: they only work by calculating probabilities based upon averages. (Stiegler and Marissal, 2016, np)

Stiegler (Stiegler and Marissala, 2016) argues that Google is effectively "destroying language" as its algorithms cause "an immense linguistic entropy" of language and thought. What does this mean? For Stiegler, Google is destroying "the idiomaticity, the singularity of language." While calculation erodes the exception as such, it leads to the destruction of difference-this is exceedingly important because every teacher from day one of their training is told to make a difference, that their profession makes a difference. Yet, while it is undoubtedly a powerful means of calculation and control, in its current iteration Google and other platforms are entropic and toxic, curtailing the linguistic capacity of natural languages. Google leads to the cognitive proletarianization of language.

We can perhaps put it slightly differently in the language of Hottois: Google somehow is leading to the transcendence of the symbolic, towards an "operative transcendence" or "dark transcendence." The algorithm is opaque to the symbolic, to the logos (Hottois, 1984, p. 20). The animal symbolicum is replaced by the species 
technical. In stark terms, the algorithms of Google challenge noetic life, that is, the life of the human mind, and all desire as such, and eliminate all defaults, including language and social communication. Google "destroys the improbable, i.e., desire, affection, attachment, identification, singularity, individuation and the feeling to exist psychically and individually" (Stiegler, 2016, p. 76)

I am told I should not be so despondent as we are living through a historical revolution in learning and the fundamental re-evaluation of knowledge practices. Perhaps a different use of the Input Method Editor IME on smartphones will be effective in fighting or curing "character amnesia." This is the argument of Professor Nicola McLelland of Nottingham University in England (McLelland, 2018) who speaks affirmatively of the changes brought about by the use of the smartphone. While others would disagree that there is no shortcut to the learning of foreign languages, she claims in the learning of a foreign language such as Chinese the smartphone "transrevolutionises" its learnability:

We always have this fear that technology is going to be disruptive in a bad way. On the whole the new technology is very enabling. In my own experience I'm trying to learn Chinese at the moment... the fact that I can draw really badly the character on my mobile phone and it can tell me what it is, it trans-revolutionises the learnability of Chinese. (McLelland, 2018, np)

What "trans-revolutionises" means semantically and logically is not entirely clear, but Wolf shares its transformative emphasis and sentiment and claims that "[t]echnology is going to bring literacy in ways we have never imagined" (Wolf, 2018, np). With both McLelland's and Wolf's affirmative statements in mind, on reflection perhaps I many well be over-egging my arguments regarding the prospects of character amnesia. Perhaps character amnesia and illiteracy will not be the serious problem in the coming decades. Perhaps the necessity for reading and writing and thinking in its traditional mode is a thing of the past. Indeed, this is the conclusion of Almog (2018, p. 28) who writes:

Moreover, in a few decades from now, we will probably be much closer to a 'paperless world', making handwriting even less important, especially if we consider the advanced voice-recognition capabilities computers already possess. Social norms may also gradually change towards a greater acceptance of character amnesia as a non-negative reality. Once this transitory stage ends, the fear of character amnesia, as well as the term itself, is likely to be water under the proverbial bridge.

In Stieglerian language this suggests that the potential neurological transformation constructs new circuits in the brain, erasing the old circuits or making them redundant. The activity thereby promotes a "mutation of knowledge" through new digital reading and writing practices. It is the philosopher of education who must catch up and understand these transformations. In "The Digital, Education, and Cosmopolitanism," Stiegler writes:

Digital technology is a form of writing, a writing that is produced at the speed of light, through machines to which we have delegated the process of reading 
and writing, organized and controlled by a planetary industrial sector established by global companies that have been in existence only a very short time. Digital reading and writing constitutes the new milieu of knowledge, in fields as diverse as astrophysics, nanophysics, biology, geography, history, mathematics, linguistics, even sports science. Therefore everything, absolutely everything, is in the process of becoming digital. We are witnessing a total mutation of knowledge, which affects at the same time embodied knowledge and life wisdom. Daily life is what is first upended, in all its dimensions. These mutations are established by the market, without any hint of a critical process that could at least provide some nuance and inflection. (Stiegler, 2015a, b, p. 160)

What are the ramifications of this mutation of knowledge with respect to the possibility of collective intelligence? The French thinker Pierre Lévy argues that we will see many kinds of new dynamic interactive writing systems in the 21 st century. New writing systems will be invented through algorithmic manipulation and collective intelligence will emerge bottom-up as it were, building on what Stiegler calls the "noetic necromass" (Stiegler, 2018) — that is, dead living matter or humus housed in vast archives, ancient libraries, schools and universities, in other words, concrete forms of human knowledge or tertiary retentions stored and passed down the generations. In an interview with Michael Peters, Pierre Lévy says (Peters, 2015, p. 263): "The next generation of writing systems will help us to filter, categorize, evaluate, analyze, visualize and generate flows of data. They will have the power of programming languages and the nuances of natural languages." The advantages of this cannot be downplayed because from more complex writing systems (interactivity, generativity and hypertextuality) the cognitive power of the human species will be enhanced, claims Lévy. The point to be noted is that learning to write in the algorithmic medium is something quite different than learning to write in the traditional typographic medium. According to Lévy, appreciating this distinction is the new educational challenge and one which will allow us to understand how augmentation and collaboration transforms our common memory. Lévy is seeking to account for the cultural revolution of passing from one form of grammatisation to another, from the typographic to the algorithmic medium.

\section{The Writing Ball}

Others however argue that the forgetting of how to write (kanji in particular) is not only a matter of the forgetting of knowledge but a pulverizing transformation and exhaustion of thinking as such (Odawara, 2016, p. 67). Indeed, the question of the loss of knowledge of how to read and write in the time of digital technologies is not a new one. Ever since the widespread public use of the World Wide Web in the early 1990s, scholars have been concerned that the information processing revolution and word processor use may lead to a decline in the ability to write and read characters by hand. Indeed, in history, there is a consistent concern over the overreliance on new technologies such as addiction to books in the 17th century or changes to computer input methods in our historical moment. Indeed, in the nineteenth century there was a widespread concern that the use of the typewriter was transforming the 
mind itself in important ways. The famous example of Nietzsche's Screibkugel or the Malling-Hansen Writing ball (Emden, 2005) is a case in point. One of the first philosophers to use a typewriter in the 19th century, Nietzsche puts it like this in a letter to composer Paul Gast: "Our writing instruments contribute to our thoughts." The use of the typewriter changes not only language but thought, in Nietzsche's case, the practice of philosophy itself is transformed. On February 16, 1882, and in more poetic form, Nietzsche expresses it thus:

The writing ball is a thing like me:/Made of iron yet easily twisted on journeys/Patience and tact are required in abundance/As well as fine fingers to use us.

Indeed, in Discourse Networks, Kittler remarks that through the use of the typewriter Nietzsche's prose "changed from arguments to aphorisms, from thoughts to puns, from rhetoric to telegram style" (Kittler, 1992, p. 193). Again I am told that I should be more positive and understand the changes pharmacologically. At the very least, we can say, there was thought. From Stiegler's perspective, Nietzsche's case is interesting because the typewriter was used pharmacologically as a poison and cure. Without it, and because of his poor eyesight, Nietzsche may have been forced to give up writing philosophy altogether. Think of a world without Nietzschean thought! Perish that thought! Think of Stephen Hawking's computer interface with its adaptive word predictor. Without such technologies, the world would have lost the thoughts of one of the 20th century's greatest scientists.

In Proust and the Squid, (Wolf, 2008, p. 226; Kurschus, 2015 p. 68) Wolf suggests that many children are losing the knowledge of how to read, that is to read deeply in the transition from a "reading brain" to a "digital brain." While children are becoming "decoders of information"- this is a "false sense of knowing." That they can decode information is not at issue. What is it stake is the distraction from "a deeper development of their intellectual potential." Discussing the plasticity of the brain and the traditional way to read and write kanji, Wolf states that the brain circuitry demanded in the visual memorization of Chinese and Japanese kanji develops more in the right hemisphere and the visual cortex. She notes that Chinese elementary students are compelled to remember several thousand characters in Chinese while noting the significant change in the 21 st century regarding the reading brain circuit. She argues that the brain develops differently with and through the screens of digital devices compared to the tactile use of concrete, print medium. The difference grants a particular affordance. As a consequence, there are different brain circuits for different writing systems. At the neuroplastic level, in reading through one medium or another, different circuits are emphasized. This point is also picked up by Serres $(2015$, p. 6$)$ who describes the brains of children who inhabit the virtual world and who struggle to hear "the old voice of the book":

These children inhabit the virtual. The cognitive sciences have shown us that using the Internet, reading or writing messages (with one's thumb), or consulting Wikipedia or Facebook does not stimulate the same neurons or the same cortical zones as does the use of a book, a chalkboard, or a notebook. They can manipulate several forms of information at the same time, yet they neither 
understand it, nor integrate it, nor synthesize it as do we, their ancestors. They no longer have the same head.

In more critical terms, Stiegler calls this the disruption to our mental capacities. In extremis, this is producing "immense disillusionment and tremendous disaffection" (Stiegler, 2012a, p. 30). Indeed, the practice of silent reading and writing is seen by many as a stressful act. Citing research by Henseler and Surkamp, Elsner claims that the reading of pure texts delinked from pictures or animation is experienced by young people often as a "stressful" act and one to be avoided (Elsner et al., 2013, p. 56).

\section{Monstrous Learning}

All of humanity's problems stem from man's inability to sit quietly in a room alone. Blaise Pascal, Pensées.

Traditionally, in learning Chinese characters one learns by hand, led by the master's hand: "One emulates. There is a sense of immediate induction through manual dexterity. There is no prior explanation as one learns by doing, by emulating the demonstration of the demonstrator. The hand of the child reproduces the movements of the hand of elders in monstrous or demonstrable ways" (Bradley, 2014, p. 48; Derrida, 1987). While smartphones and digital technologies are widely and enthusiastically embraced as a liberation, in some ways, arguably an escape from the disciplinary society, the question remains why is it so difficult to sit by yourself, to think in silence, to read and write in the depths of solitude. Yet this position is at odds with that of Seb Ward who writes on November 1st, 2018, in his article 'If you're feeling lonely at university, you're not alone':

Get out of your room-I found staying in my room to be toxic. Sitting in your room alone is likely to make you feel lonelier than you are. Try going to the library or to a cafe to work-anywhere where conversation is taking place and you're not deafened by silence. (Ward, 2018, np)

What does it mean to be deafened by silence? The reflection by this blogger for Times Higher Education is interesting because it is quite the opposite view from the phenomenological philosopher Emmanuel Levinas, who like Pascal centuries before writes scathingly of the so-called cafe society, which is to say, a society which lacks relations, or in the parlance of Stiegler following Simondon, which lacks the capacity to form transindividuation circuits between the generations:

The cafe holds open house, at street level. It is a place of casual social intercourse, without mutual responsibility. One goes in without needing to. One sits down without being tired. One drinks without being thirsty. All because one does not want to stay in one's room. You know that all the evils in the world occur as a result of our incapacity to stay alone in our room. The cafe is not a place. It is a non-place for a non-society, for a society without solidarity, 
without tomorrow, without commitment, without common interests, a game society. (Levinas and Aronowicz, 2019; DSS 31; NTR 111)

\section{Gymnastics of Silence}

How does one comport oneself towards solitude and silence? For Foucault, good handwriting "presupposes a gymnastics." What is the nature of this gymnastics? A regimen is demanded which codes the body "in its entirety" (Foucault, 1977, p. 152). My point in citing Foucault is that there is a forgetting of the discipline of the body. This is exemplified in character amnesia.

The teaching of literacy, of deep reading and writing, demands a renewed sense of askesis (exercise, asceticism), of textual and gymnastic exercises for self-transformation. This is to rethink the question of a gymnastics of memory and silence, of solitude, of thoughtful reflection, of mindfulness, of brain muscle-building. I claim the gymnastics of sitting still and doing nothing, of learning to be alone is all the more pressing in the time of the coronavirus pandemic. Following Foucault, such a gymnastic practice demands a whole new routine, a rigorous recoding and reinvestment in the body. Writes Foucault (1977, p. 152) of the disciplined body:

A well-disciplined body forms the operational context of the slightest gesture. Good handwriting, for example, presupposes a gymnastics-a whole routine whose rigorous code invests the body in its entirety, from the points of the feet to the tip of the index finger... A disciplined body is the prerequisite of an efficient gesture.

The efficacy of a gesture? The algorithm is efficient yet leads to the deficiency and proletarianization of the human, according to Stiegler. To counter this, in the Japanese context, Komatsu and Rappleye offer the following albeit nationalist and chauvinist prescription, finding efficacy in Japanese cultural practices and especially the concept of hansei (反省) (Komatsu and Rappleye 2020). For example, in good handwriting. Hansei becomes a question of discipline and further docilisation of the body. Hansei emphasises self-negation, attention to manners, the use of polite language, the rituals of school lunch and school cleaning, lesson study, and so on. Yet from my point of view, I cannot romanticise this nationalistic and chauvinistic way, and so it is difficult to affirm a return to the workhouse and the panopticon as a remedy for the decline in language learning.

\section{Tertiary Retentions}

Stiegler draws on Wolf's work on the neurophysiology of reading to appreciate the role of tertiary retentions. For him, the question is one of hypomnesis, that is, the technical exteriorization of memory, which is contrasted with anamnesis, or the embodied act of memory. Stiegler's point is that tertiary levels of attention act to reconstruct experience. Following Husserl, they transform how we perceive the world (primary retention), and how we work with our recollection and memory of experience (secondary retention). He observes that "the brain is 
literally written by the socio-technical organs, and where our own brains, which she [Maryanne Wolf] calls 'reading brains,' were once written by alphabetical writing, but are now written by digital writing" (Stiegler, 2012a, p. 35). As we have seen, Stiegler suggests that writing, a relatively new invention in human history of some two thousand years, has manifestly restructured our brains and changed the way we think. Writing has altered our intellectual evolution. And so too with digital learning. For her part, Wolf is primarily concerned with the changes which occur when young people skim information rather than deeply appreciate a text. As she says the question is: "When to skim and when to dive deeply something different happens." On the question of deep reading, Wolf discusses her own struggle:

I had become a skim reader who was superimposing upon a text which required the apperception of thought and beauty. I was word spotting and only when I regained my old reading self and I could take up the pace demanded by the text, not superimposed by me, only then did I feel I could truly read the book again. I started all over and I read it from the beginning again and that's when I remembered who I was as a reader. It was a wake up call from myself. (Wolf, 2018, np)

Wolf asks how we can establish the conditions for new readers to develop "a bi-literate brain," to know when to skim and when to dive deeply. In Stiegler's argot this knowledge is how to use digital devices pharmacologically, and as he has been consistently argued, therapeutically and curatively. Following this argument, my point is that if technology intercedes in the learning of language (writing kanji on your smartphone for example) this impacts on the psychic and sensory apparatus or noein of the user. McLelland's celebration of the trans-revolutionary nature of language learning mentioned above does not observe this critically important effect. Stiegler warns that behind this seemingly innocent process of language learning via digital technologies is a whole industry of marketing and powerful manipulation. As such, Stiegler throws down the gauntlet to the university qua institution to deploy digital technologies in non-toxic, curative and therapeutic ways, to foster deep attention among the student body. It must do so or cease to be so. As he says: "Universities must take over the digital, for it is a matter of their survival. The university will be the promulgator of knowledge; it will not be simply the dispenser of education. Put another way, it will become digital or it will no longer exist" (Stiegler et al., 2015, p. 162). It is insufficient to merely stand back and allow students to give themselves over entirely to technology (Mui and Murphy 2020). Stiegler challenges the university as an institution to respond and suggests what the university must do faced with the task ahead (Stiegler, 2014a):

It is to reconstruct deep attention in an age in which a global mnemotechnical system is placing psycho-technologies under the hegemonic control of marketing, the effects of which are highly toxic...even if some curative effects also occur. 


\section{The Threat of Linguistic Entropy}

Not only the Chinese, French, and English languages are imperiled by automatic translation services and assisted language learning but in toto the main languages of the world on earth are in danger. Translation services offered by Google and its ilk are leading to an "immense linguistic entropy." This is Stiegler's consistent emphasis. Closed, mechanical systems of language become entropic leading to "the destruction of differences." For a neuroscientist like Wolf, her concern is to understand how the brain can precisely make exceptions through reorganizing the temporal flux in memory. Consistent with Stiegler, she makes the point that mechani$\mathrm{cal}$, accelerating processes functioning almost instantaneously are productive of the entropy of difference and exception. Against this, we need new habits of thought, of reading, of deep reading. What are such habits of solitude, of sitting by yourself, of nestling down into thinking deeply, of taking your time and slowing down? Why is this habitual mode of being in the world so difficult for so many young people? In this slowing down or lingering, one finds the point where something new comes into the world. This is both the slowing down of what Wolf speaks of or the circuit breakers of what Berardi, following Deleuze, talks about. This is the serendipitous event, a fillip and spark in the brain, when two things are juxtaposed and something new is brought into the world for the first time. We should be mindful about the addictive habit of constant checking of email, the constant checking of social networking, the habit of skim reading rather than deep reading a text. These are toxic addictive habits which fail education, habits which we would do well to kick. Against the accelerationist, extropian, transhuman manifestos, which affirm far too readily these addictive habits, in Proust and the Squid (p. 213), Wolf writes:

I differ with Kurzweil's implicit assumption that an exponential acceleration of thought processes is altogether positive. In music, in poetry, and in life, the rest, the pause, the slow movements are essential to comprehending the whole. Indeed, in our brain there are 'delay neurons' whose sole function is to slow neuronal transmission by other neurons for mere milliseconds. These are the inestimable milliseconds that allow sequence and order in our apprehension of reality, and that enable us to plan and synchronize soccer moves and symphonic movements.

With Katherine Hayles (2007), Stiegler has consistently claimed that young brains troubled by hyper-attention problems such ADHD show increasing difficulty in reaching deep attention (Bradley, 2015; Lee, 2020). That there is a forgetting of old systems of retention, memory and learning opens the way for manipulation and control through "industrial temporal objects." For Stiegler, in the "organological age of attention formation," writing and reading are psycho technologies and mechanisms for the production of maturity in the Enlightenment sense. While Michel Serres (2015; see Bradley and Kennedy, 2015) insists knowledge now resides "all in computers"-in the huge databases that young people can access within a fraction of a second on their hand held digital devices, and insists that knowledge- - long held captive in libraries and by elite intellectuals - has been made ready-on-demand by electronic media, particularly online search engines, students are liberated to frolic 
in "the incandescent joy of invention" (Serres, 2015, p. 19), Stiegler warns that the outsourcing of retentional memory to mobile devices has sinister and detrimental ramifications. While Serres suggests seemingly affirmatively that we are witnessing the end of a certain era of knowledge (Serres, 2015, p. 28) as the Thumbelina generation possesses in the hand the entire knowledge promised by the university qua institution, that is knowledge "accessible, from any portal, via the web, from Wikipedia," Stiegler for his part demands the radically reconstruction of knowledge, "to revisit completely the base of knowledge" (Stiegler and Sloterdijk, 2016). Both are concerned with the ramifications which follow from how the subject of thinking has changed or mutated.

While few people would bemoan the inordinate amounts of recorded and reticulated knowledge available, at more than any time in human history, to virtually anyone with access to a computer and an Internet account, Stiegler is more cautious insisting that we have to re-imagine what knowledge is and what will be in this new digital terrain. Stiegler believed we should be cautious about the destruction of attention and the way educational institutions like the university-once the preserve of the noetic necromass - are becoming more like programming industries by the day. We must understand that the university is a competitor for the attention of young people. The university is an institution for the individuation or transindividuation of young people and we should be mindful of the fact that while there is exteriorization of memory, there is not the corresponding amount of re-interiorisation of knowledge. For Stiegler, following Simondon, the condition of possibility of the transindividual is the existence of technical objects which support and reactivate social sharing. The university as an intermediary and utiliser of technical objects, as a site for the storage of the noetic necromass has a key role in sustaining transindividuation circuits. Not to appreciate this is to suffer from intellectual amnesia or bêtise of historical proportions. The question then is how to create, practice and think of a general organology of reticulated reading and writing to create a new link between the psychosomatic organs of the body and the noetic soul, that is, the enlivened human mind as such.

\section{References}

Almog, G. (2018). Getting out of hand? Examining the discourse of "character amnesia." Modern Asian Studies, 53(2), 690-717.

Almog, G. (2019). Reassessing the evidence of Chinese "character amnesia." The China Quarterly, 238, 524-533.

Benjamin, A. E. (1995). Complexity: Architecture, art, philosophy. Academy Group.

Berardi, F. (2012). The uprising: On poetry and finance. Los Angeles, Calif: Semiotext(e.

Bradley, J. P. N. (2014). The Zerrissenheit of subjectivity. Tamkang Review, 44(2), 37-62.

Bradley, J. P. N. (2015). Stiegler contra Robinson: On the hyper-solicitation of youth. Educational Philosophy and Theory, 47(10), 1023-1038.

Bradley, J. P. N. (2020). From hypochondria to disruption: Hegel and Stiegler on youth. Philosophical Inquiry in Education, 27(2), 122-134.

Bradley, J. P. N., \& Kennedy, D. H. (2015). On giving ourselves over to industrial temporal objects. Journal of Engaged Pedagogy, 14(1), 71-79.

Bradley, J. P. N., Poje, J., Kennedy, D. H., Cabell, C., \& Cole, D. R. (2018). From which point do we begin? On combining the multiliteral and multiperspectival. Stem Journal, 19(2), 65-93. 
Cole, D. R., \& Bradley, J. P. N. (2017). Educational philosophy and new French thought. Routledge.

Derrida, J. (1987). Geschlecht II, Heidegger's hand. In J. Sallis (Ed.), Deconstruction and philosophy: The texts of Jacques Derrida (pp. 161-196). University of Chicago Press.

During, E., Stiegler, B., \& Dillet, B. (2017). Philosophising by accident: Interviews with Élie during. Edinburgh University Press.

Elsner, D., Helff, S., \& Viebrock, B. (2013). Films, graphic novels and visuals: Developing multiliteracies in foreign language education: an interdisciplinary approach. LIT.

Emden, C. (2005). Nietzsche on language, consciousness, and the body. University of Illinois Press.

Foucault, M. (1977). Discipline and punish: The birth of the prison. Penguin Books.

Guattari, F. (2014). The three ecologies. Bloomsbury Academic.

Hayles, N. K. (2007). Hyper and deep attention: The generational divide in cognitive modes. Profession, 2007(1), 187-199.

Heathfield, A, Glendinning, H \& Stiegler, B. (2015). Technologies of Spirit: A conversation with Bernard Stiegler. https://vimeo.com/ondemand/technologiesofspirit. Accessed 19 Sept 2019.

Heidegger, M. (1968). What is called thinking? Harper \& Row.

Heidegger, M. (1992). Parmenides. Indiana University Press.

Herrenschmidt, C. (2007). Les trois écritures: Langue, nombre, code. Gallimard.

Hottois, G. (1984). Le signe et la technique. La philosophie à l'épreuve de la technique. Aubier.

Kittler, F. A. (1992). Discourse networks, 1800/1900. Stanford University Press.

Komatsu, H., \& Rappleye, J. (2020). Reimagining modern education: Contributions from modern Japanese philosophy and practice? ECNU Review of Education, 3(1), 20-45.

Kurschus, S. (2015). European book cultures: Diversity as a challenge. Springer Fachmedien Wiesbaden.

Lee, S. (2020). Educational methods and cognitive modes: Focusing on the difference between Bernard Stiegler and N Katherine Hayles. Educational Philosophy and Theory, 52(4), 376-383.

Levinas, E., \& Aronowicz, A. (2019). Nine Talmudic readings. Indiana University Press.

McLelland, N. (2018). "The rise of translation and the death of foreign language learning." BBC Radio 3: Free Thinking.

Mui, C. L., \& Murphy, J. S. (2020). The university of the future: Stiegler after Derrida. Educational Philosophy and Theory, 52(4), 455-465.

Odawara, H. (2016). “Kantan na kanji ga kakenai. Korette sumaho ga genin?” [Can't write simple kanji? Is the smartphone the cause?] Jijico: http://jijico.mbp-japan.com/2016/02/29/articles19221.html. Accessed 9 Oct 2020.

Peters, M. (2015). Interview with Pierre A. Lévy, French philosopher of collective intelligence. Open Review of Educational Research, 2(1), 259-266.

Plant, S. (2003). On the mobile: The effects of mobile telephones on social and individual life. Motorola Corporation.

Rochard J., Birgé J. J. \& Stiegler, B. (2020). Bernard Stiegler, la musique est la première technique du désir. Hommage a Bernard Stiegler. Des Allumes du Jazz 21. https://www.lesallumesdujaz z.com/actualite-la-musique-est-la-premiere-technique-du-desir-hommage-a-bernard-stiegler, 721 . html\#player1 ?catid=0\&trackid $=0$. Accessed 27 Dec 2020.

Rouvroy, A., \& Stiegler, B. (2016). The digital regime of truth: From the algorithmic governmentality to a new rule of law. La Deleuziana, 3, 6-29.

Serres, M. (2015). Thumbelina: The culture and technology of millennials. Rowman \& Littlefield International.

Stiegler, B. (1998). Technics and time: 1. Stanford University Press.

Stiegler, B. (2011). Decadence of industrial democracies: (Vol. 1). Polity Press.

Stiegler, B., et al. (2012a). Die Aufklärung in the age of philosophical engineering. In M. Hildebrandt (Ed.), Digital enlightenment yearbook (pp. 29-39). IOS Press.

Stiegler, B. (2012b). Uncontrollable societies of disaffected individuals. Polity.

Stiegler, B. (2014a). What makes life worth living: On pharmacology. Wiley.

Stiegler, B. (2014b). Colloque "Les enfants face aux écrans." Mairie du XIXe arrondissement de Paris, à l'initiative de Jacques Brodeur (Edupax) et avec le soutien du maire, François Dagnaud. [Children in front of screens. 19th arrondissement of Paris town hall, the initiative of Jacques Brodeur (Edupax) and mayoral support (30 April 2014).

Stiegler, B. (2015a). States of shock: Stupidity and knowledge in the twenty-first century. Polity.

Stiegler, B. (2015b). "Nous devons sortir de notre relation addictive et débile avec les instruments numériques." [We need to get out of our addictive and debilitating relationship with digital instruments]. http://www.ventscontraires.net. Accessed 10 July 2019. 
Stiegler, B. (2016). Dans la disruption. Comment ne pas devenir fou? Le liens qui libérent.

Stiegler, B. (2018). Qu'appelle-t-on panser? 1 L'immense régression. Les Liens qui Libèrent.

Stiegler, B., \& Nony, A. (2015). Bernard Stiegler on Automatic Society as told to Anaïs Nony. The Third Rail, 5, 16-17.

Stiegler, B., \& Marissal, P. (2016). "Nous devons rendre aux gens le temps gagné par l'automatisation." [We need to give people back the time saved by automation]. https://www.humanite.fr/. Accessed 7 Apr 2020.

Stiegler, B., Audi, P., \& Bedel, C. (2015). Digital technology. Education and Cosmopolitanism Cités, $63(3), 13$

Stiegler, B., \& Sloterdijk, P. (2016). Welcome to the Anthropocene. Debate with philosophers Peter Sloterdijk and Bernard Stiegler. Radboud University.

Stiegler, B., \& Ross, D. (2017). Automatic society: The future of work (Vol. 1). Wiley.

Tinnell, J. (2015). Grammatization: Bernard Stiegler's theory of writing and technology. Computers and Composition, 37, 132-146.

Ward, S. (2018). "If you're feeling lonely at university, you're not alone." https://www.timeshighereduc ation.com/student/blogs/if-youre-feeling-lonely-university-youre-not-alone. Accessed 4 May 2019.

Wolf, M. (2008). Proust and the squid: The story and science of the reading brain. Harper Perennial.

Wolf, M. (2018). "Books, tablets and screens: The science of reading in a digital age." CPRE Knowledge Hub. CPREHub.org

Wolf, M. (2019). Reader, come home: The reading brain in a digital world. Harper.

Wolf, M., Stupar, L., \& Stiegler, B. (2015). Proust et le calamar. Abeille et Castor.

Zhou, W., Kwok, V. P. Y., Su, M., Luo, J., \& Tan, L. H. (2020). Children's neurodevelopment of reading is affected by China's language input system in the information era. NPJ Science of Learning, 5, 1.

Publisher's Note Springer Nature remains neutral with regard to jurisdictional claims in published maps and institutional affiliations. 